\title{
Equivalent Modeling of DFIG-Based Wind Power Plant Considering Crowbar Protection
}

\author{
Qianlong Zhu, Ming Ding, and Pingping Han \\ Hefei University of Technology, Hefei, Anhui 230009, China \\ Correspondence should be addressed to Qianlong Zhu; zhuqianl19@163.com
}

Received 24 February 2016; Accepted 30 June 2016

Academic Editor: Jason Gu

Copyright ( 2016 Qianlong Zhu et al. This is an open access article distributed under the Creative Commons Attribution License, which permits unrestricted use, distribution, and reproduction in any medium, provided the original work is properly cited.

\begin{abstract}
Crowbar conduction has an impact on the transient characteristics of a doubly fed induction generator (DFIG) in the short-circuit fault condition. But crowbar protection is seldom considered in the aggregation method for equivalent modeling of DFIG-based wind power plants (WPPs). In this paper, the relationship between the growth of postfault rotor current and the amplitude of the terminal voltage dip is studied by analyzing the rotor current characteristics of a DFIG during the fault process. Then, a terminal voltage dip criterion which can identify crowbar conduction is proposed. Considering the different grid connection structures for single DFIG and WPP, the criterion is revised and the crowbar conduction is judged depending on the revised criterion. Furthermore, an aggregation model of the WPP is established based on the division principle of crowbar conduction. Finally, the proposed equivalent WPP is simulated on a DIgSILENT PowerFactory platform and the results are compared with those of the traditional equivalent WPPs and the detailed WPP. The simulation results show the effectiveness of the method for equivalent modeling of DFIG-based WPP when crowbar protection is also taken into account.
\end{abstract}

\section{Introduction}

With the rapid development of wind power generation and power electronics, the doubly fed induction generator (DFIG) has recently become the most commonly used wind turbine in wind power plant (WPP) based on its characteristics of maximum power point tracking (MPPT) [1], decoupled control of active and reactive powers [2], the use of a power convertor with a rated power of $25 \%$ of total system power [3], and so forth. To investigate the effect of the ongoing changes in power systems due to the increasing penetration of wind power, a wide range of studies, from steady-state to transient, are necessary. A detailed WPP model, in which the dynamics of each wind turbine and the internal network are fully represented, is not suitable as it could significantly increase the order of the mathematical model of the power system to be solved and thus influence the overall simulation time. As a result, the equivalent WPP model is generally recommended for reflecting the collective response of the whole WPP on large power systems.
Equivalent WPPs using aggregated wind turbines are classified as either the single-machine representation or the multiple-machine representation [4]. In the first case, the actual WPP is modeled as a unique rescale wind turbine in the single-machine representation. Accordingly, this is rational when all wind turbines are operating in an identical condition, whereas that might not be the case in real-world system operation. Nowadays, in order to improve the conformity of the single-machine representation with the actual WPP, numerical identification methods for optimizing the parameters of equivalent models are applied. The optimized objects include the generator $[5,6]$, power convertor [7], and passive frequency-dependent network [8]. The fuzzy logic system is also utilized to compute the mechanical torque compensating factor, which is integrated into a singlemachine aggregated WPP [9].

In the second case, study of the multiple-machine representation focuses on selecting reasonable clustering indices by quantifying and abstracting key features of wind turbines. The coherency method is presented in $[10,11]$ by 


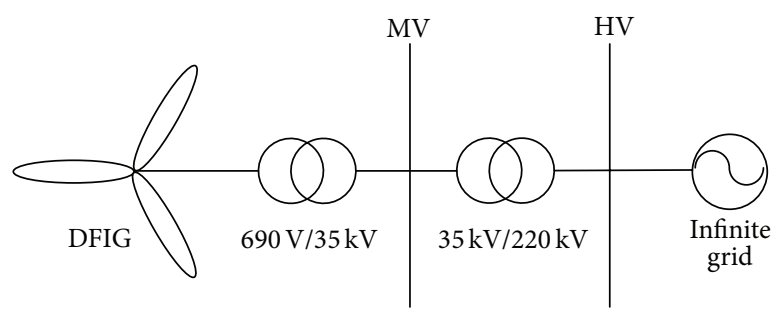

FIGURE 1: Schematic of DFIG generation system.

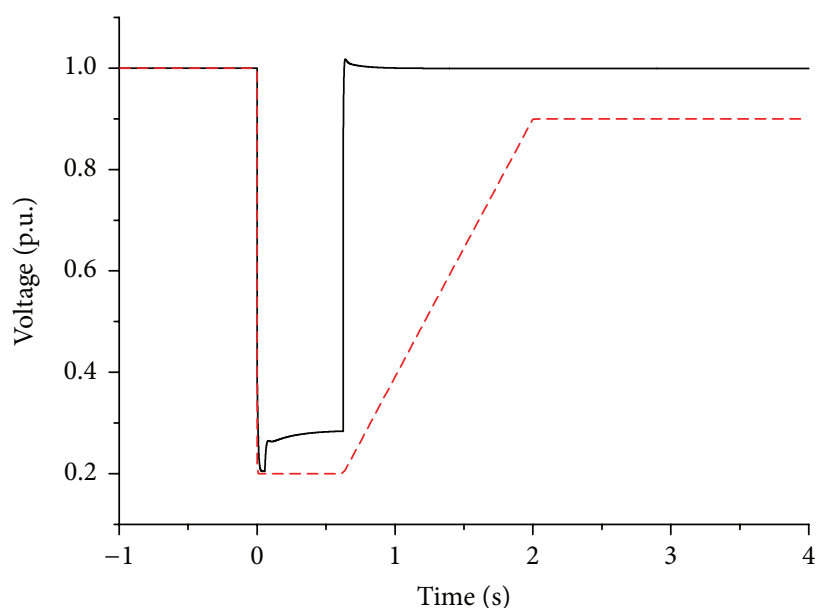

- DFIG model

--- Grid code

(a)

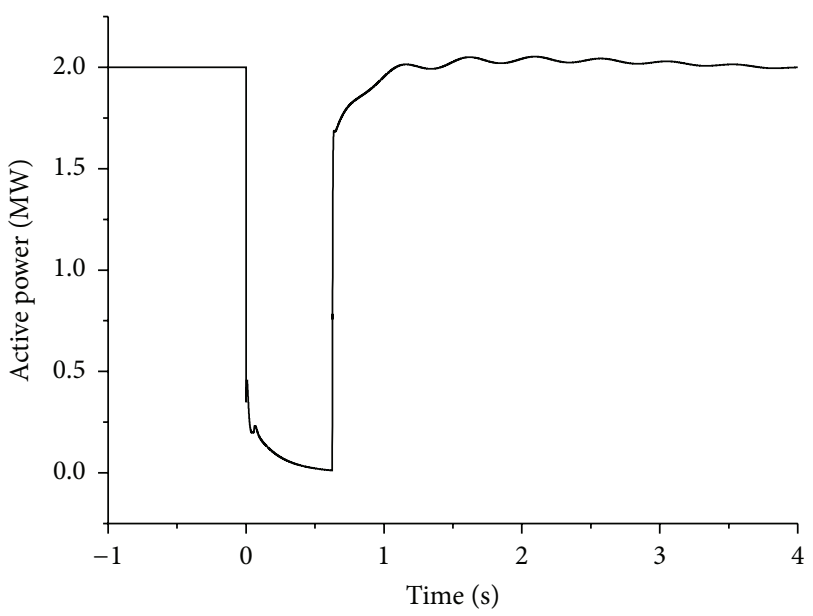

DFIG model

(b)

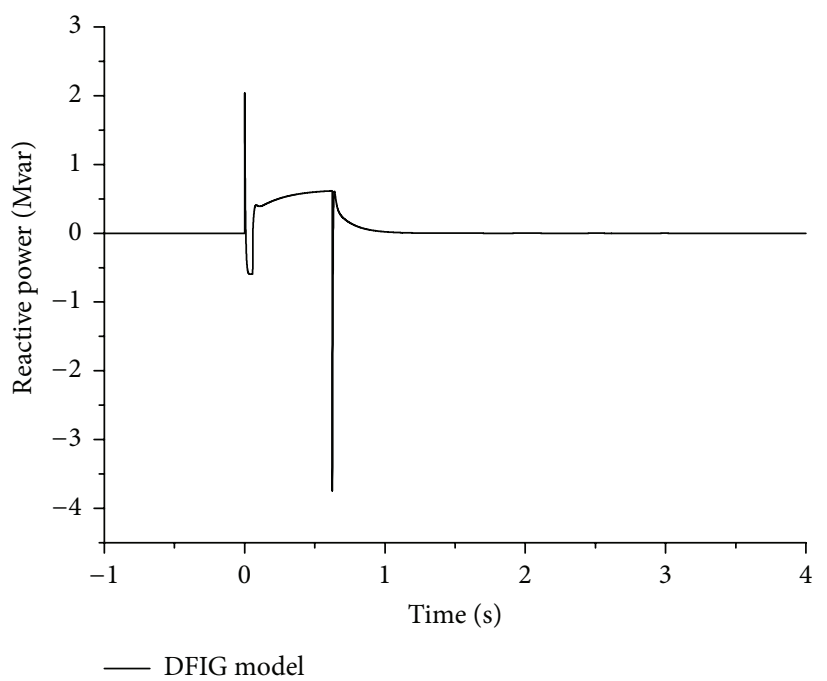

(c)

FIgure 2: (a) PCC voltage of the DFIG model. (b) PCC output active power. (c) PCC output reactive power.

clustering wind turbines with similar wind speed. In [12], the wind direction is implemented. To represent the power loss on the collective network within the WPP, a method of calculating the equivalent impedance is introduced in [13].
Moreover, research work in [14] analyzes the impact of the line impedance on the diversity in the voltage profile of each wind turbine and describes a voltage-profile-based approach to develop multiple-machine aggregated WPP. In addition, a 


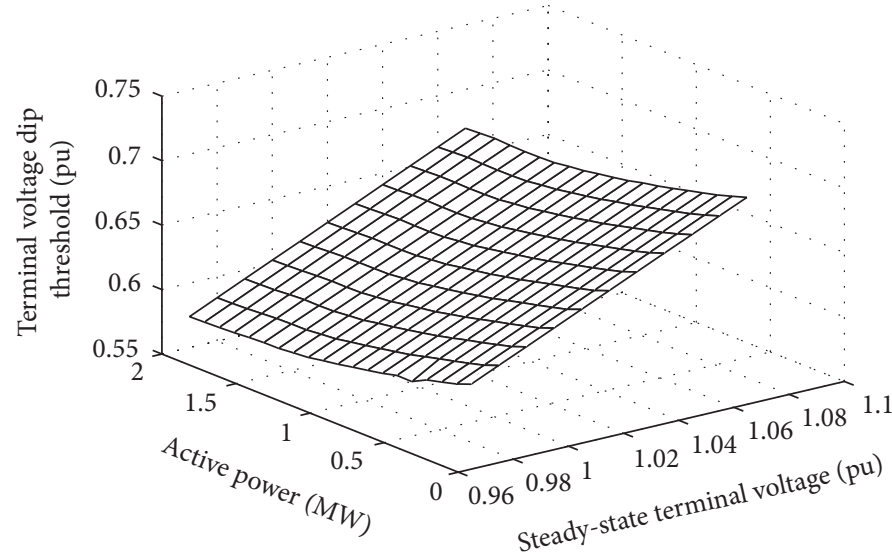

(a)

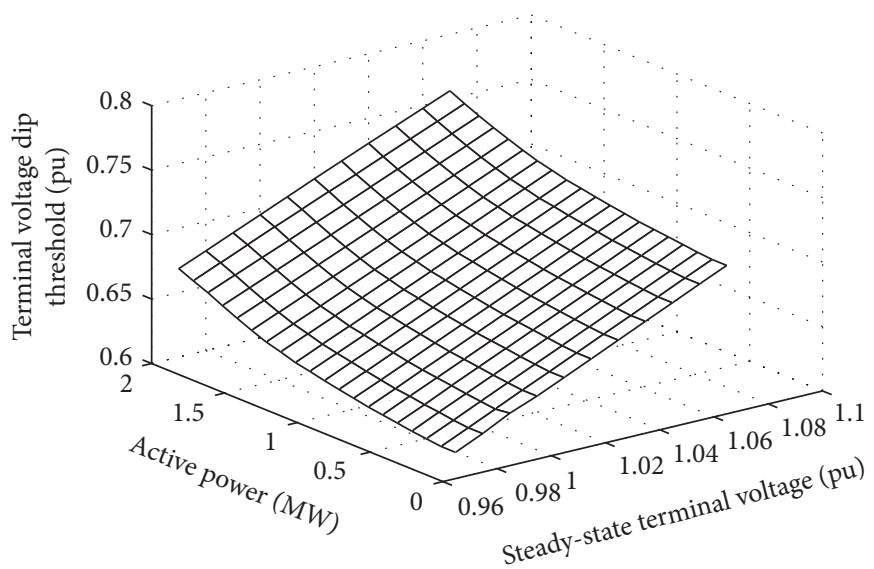

(b)

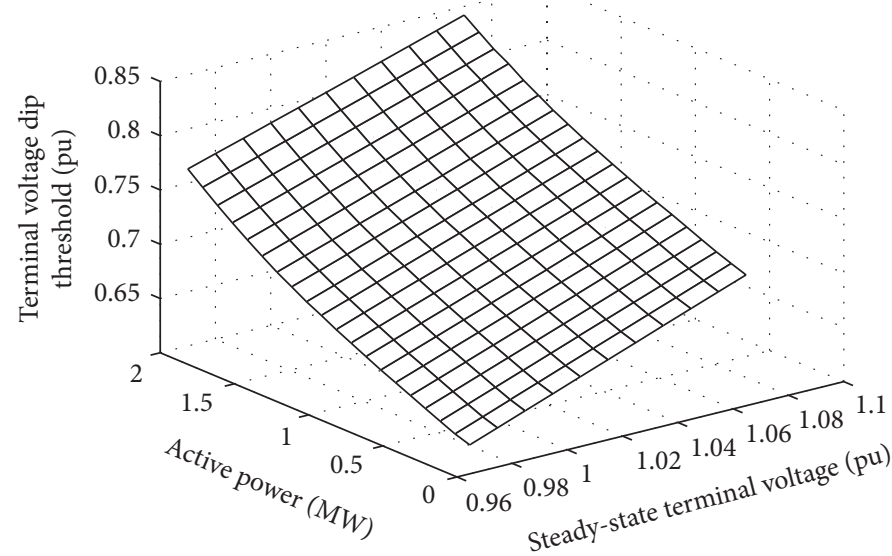

(c)

FIGURE 3: Terminal voltage dip threshold of DFIG: (a) power factor $=-0.95$, (b) power factor $=1$, and $(\mathrm{c})$ power factor $=0.95$. 


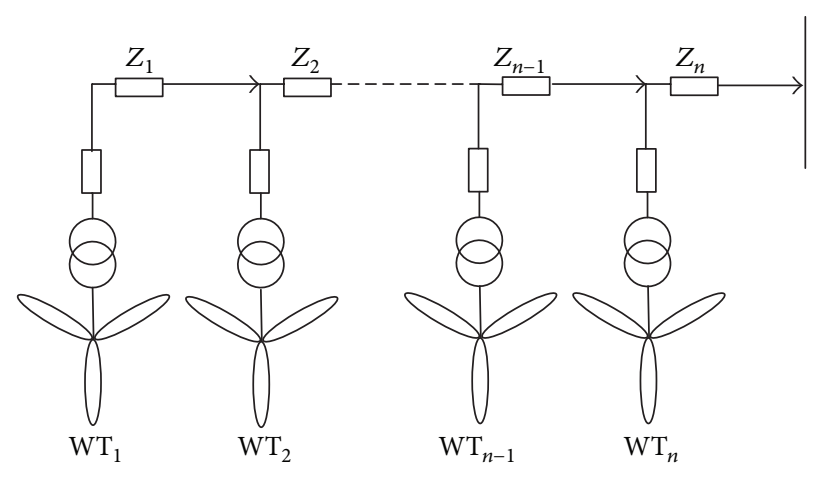

FIGURE 4: Daisy-chain physical diagram of the WPP.

clustering index considering the influence of fault types on coherency is depicted in [15].

Compared with conventional power resources, wind resources are stochastic and fluctuating. Equivalent models of an actual WPP might change due to different operating conditions. Therefore, the actual application should be based on historical data for the specific WPP and establish a probabilistic equivalent WPP $[13,16,17]$. This makes the equivalent WPP very practical and easy to use.

On the basis of previous equivalent methods, the research hot-spot has gradually shifted to the validation and analysis of equivalent WPPs using field measurement data. The primary focus of reference [17] is to explain that the multiple-machine representation should take the diversity in protection conduction into account by investigating the discrepancies between the simulation results and the actual measurement. Perdana et al. [18] and Singh et al. [19] explore methods for validating the equivalent WPPs for SCIG-based and DFIG-based WPP, respectively. Meanwhile, reference [20] supports the fact that traditional clustering indices fail to cluster wind turbines when crowbar protection is enabled. Therefore, it is necessary to develop an equivalent method for modeling WPPs considering system protection.

This paper proposes a new equivalent method for modeling WPPs when the crowbar protection is taken into account. Based on the rotor current of the DFIG after an external three-phase short-circuit fault, the terminal voltage dip threshold is determined and from this it can be identified whether the crowbar protection is activated. Then, the threshold is revised based on the influence of the chain topology of the WPP. The revised terminal voltage dip threshold can be utilized to judge whether the crowbar is conducting. Furthermore, the equivalent WPP is established based on the division principle of crowbar conduction. Finally, the proposed equivalent WPP is simulated by the DIgSILENT PowerFactory platform and the results are compared with those of traditional equivalent WPPs and the detailed WPP. The simulation results validate the effectiveness of the equivalent method for modeling DFIGbased WPP.

\section{Postfault Rotor Current Transient Analysis of DFIG}

2.1. Postfault Rotor Current Calculation. Using the motor conversion, the stator and rotor voltages and fluxes in a synchronously rotating $d$-q reference frame are given by

$$
\begin{aligned}
& u_{s}=R_{s} i_{s}+\frac{d \psi_{s}}{d t}+j \omega_{1} \psi_{s}, \\
& u_{r}=R_{r} i_{r}+\frac{d \psi_{r}}{d t}+j \omega_{s} \psi_{r}, \\
& \psi_{s}=L_{s} i_{s}+L_{m} i_{r}, \\
& \psi_{r}=L_{m} i_{s}+L_{r} i_{r},
\end{aligned}
$$

where $u, i$, and $\psi$ represent voltage, current, and flux, respectively. $R$ is the resistance, and $L$ is the inductance. Subscripts $s$ and $r$ denote the stator and rotor quantities, respectively. $L_{m}$ is the mutual inductance. $\omega_{1}$ and $\omega_{s}$ are the synchronous speed and the slip speed, respectively.

One DFIG is connected to the infinite grid through a grounding transformer and a tertiary transformer, as shown in Figure 1. It is assumed that, at $t=t_{0}$, an external threephase short-circuit fault occurs, and, as a result, the terminal voltage of the DFIG abruptly changes from the steady-state voltage $u_{s 0}$ to the remaining voltage $u_{s k}$. The solution of (1) for $t>t_{0}$ can be written as

$$
\begin{aligned}
\psi_{s}= & \frac{u_{s k}}{j \omega_{1}}+\left(\frac{u_{s 0}}{j \omega_{1}}-\frac{u_{s k}}{j \omega_{1}}\right) e^{-j \omega_{1} t} e^{-t / T_{s}}, \\
\psi_{r}= & \frac{u_{r}(0)}{j \omega_{s}+1 / T_{r}}-\frac{A R_{r} u_{s k}}{j \omega_{1}\left(j \omega_{s}+1 / T_{r}\right)} \\
& -\frac{A R_{r}\left(u_{s 0}-u_{s k}\right)}{j \omega_{1}\left(-j \omega_{r}+1 / T_{r}-1 / T_{s}\right)} e^{-j \omega_{1} t} e^{-t / T_{s}} \\
& +C_{1} e^{-j \omega_{s} t} e^{-t / T_{r}}
\end{aligned}
$$

where $u_{r}(0)$ is the prefault rotor voltage. $T_{s}=\left(L_{s} L_{r}-\right.$ $\left.L_{m}^{2}\right) /\left(L_{r} R_{s}\right)$ is the stator decay time constant. $T_{r}=\left(L_{s} L_{r}-\right.$ 
TABLE 1: Model parameters.

\begin{tabular}{|c|c|c|c|c|}
\hline \multirow{4}{*}{ Generator } & Rater power/MW & 2 & Rated stator voltage/V & 690 \\
\hline & Rated frequency/Hz & 50 & $X_{m} / \mathrm{pu}$ & 3.5 \\
\hline & $R_{s} / \mathrm{pu}$ & 0.01 & $X_{s} / \mathrm{pu}$ & 0.1 \\
\hline & $R_{r}(\mathrm{pu})$ & 0.01 & $X_{r} / \mathrm{pu}$ & 0.1 \\
\hline Grounding transformer & S/MVA & 2.5 & $X_{T} / \%$ & 6 \\
\hline Tertiary transformer & S/MVA & 150 & $X_{T} / \%$ & 13.5 \\
\hline Crowbar protection & Maximum rotor current/pu & 2 & $R_{\mathrm{cr}} / \mathrm{pu}$ & 0.1 \\
\hline \multicolumn{5}{|c|}{ Overhead line } \\
\hline LGJ-240/35 & $r_{0}(\Omega / \mathrm{km})$ & 0.131 & $x_{0}(\Omega / \mathrm{km})$ & 0.372 \\
\hline LGJ-300/220 & $r_{0}(\Omega / \mathrm{km})$ & 0.107 & $x_{0}(\Omega / \mathrm{km})$ & 0.414 \\
\hline
\end{tabular}

$\left.L_{m}^{2}\right) /\left(L_{s} R_{r}\right)$ is the rotor decay time constant. $\omega_{r}$ and $C_{1}$ represent the rotor electrical angular speed and the integral constant, respectively, and $A=-L_{m} /\left(L_{s} L_{r}-L_{m}^{2}\right)$.

When the DFIG operates in the stator voltage vector oriented control mode, $u_{s d}=U_{s}, u_{s q}=0$. Thus, the relationship between the output powers, voltage, and current can be written as

$$
\begin{aligned}
P_{s} & =-\frac{3}{2}\left(u_{s d} i_{s d}+u_{s q} i_{s q}\right)=-\frac{3}{2} U_{s} i_{s d} \\
Q_{s} & =-\frac{3}{2}\left(u_{s q} i_{s d}-u_{s d} i_{s q}\right)=\frac{3}{2} U_{s} i_{s q}
\end{aligned}
$$

where $U_{s}=\left|u_{s 0}\right|$ is the amplitude of the steady-state terminal voltage.
Based on (1) and (3), the prefault rotor voltage $u_{r}(0)$ can be described as

$$
\begin{gathered}
u_{r d}(0)=\frac{2}{3} \frac{1}{\omega_{1} L_{m} U_{s}}\left(R_{r} \omega_{1} L_{s} P_{s}+R_{s} \omega_{s} L_{r} P_{s}\right. \\
\left.+\omega_{1} \omega_{s} L_{s} L_{r} \sigma Q_{s}-R_{s} R_{r} Q_{s}+\frac{3}{2} \omega_{s} L_{r} U_{s}^{2}\right), \\
u_{r q}(0)=\frac{2}{3} \frac{1}{\omega_{1} L_{m} U_{s}}\left(\omega_{1} \omega_{s} L_{s} L_{r} \sigma P_{s}-R_{s} R_{r} P_{s}\right. \\
\left.-R_{r} \omega_{1} L_{s} Q_{s}-R_{s} \omega_{s} L_{r} Q_{s}-\frac{3}{2} R_{r} U_{s}^{2}\right),
\end{gathered}
$$

where $\sigma=1-L_{m}^{2} /\left(L_{s} L_{r}\right)$.

From (1), the rotor current $i_{r}$ is derived as follows:

$$
i_{r}=-\frac{L_{m}}{L_{s} L_{r}-L_{m}^{2}} \psi_{s}+\frac{L_{s}}{L_{s} L_{r}-L_{m}^{2}} \psi_{r} .
$$

According to (2), (4), and (5), the dynamic representation for rotor current of the DFIG can be written as

$$
\begin{aligned}
i_{r}= & -\frac{L_{m}}{L_{s} L_{r}-L_{m}^{2}}\left[\frac{u_{s k}}{j \omega_{1}}+\left(\frac{u_{s 0}}{j \omega_{1}}-\frac{u_{s k}}{j \omega_{1}}\right) e^{-j \omega_{1} t} e^{-t / T_{s}}\right] \\
& +\frac{L_{s}}{L_{s} L_{r}-L_{m}^{2}}\left[\frac{(2 / 3)\left(1 / \omega_{1} L_{m} U_{s}\right)\left(R_{r} \omega_{1} L_{s} P_{s}+R_{s} \omega_{s} L_{r} P_{s}+\omega_{1} \omega_{s} L_{s} L_{r} \sigma Q_{s}-R_{s} R_{r} Q_{s}+(3 / 2) \omega_{s} L_{r} U_{s}^{2}\right)}{j \omega_{s}+1 / T_{r}}\right. \\
& +\frac{j(2 / 3)\left(1 / \omega_{1} L_{m} U_{s}\right)\left(\omega_{1} \omega_{s} L_{s} L_{r} \sigma P_{s}-R_{s} R_{r} P_{s}-R_{r} \omega_{1} L_{s} Q_{s}-R_{s} \omega_{s} L_{r} Q_{s}-(3 / 2) R_{r} U_{s}^{2}\right)}{j \omega_{s}+1 / T_{r}}-\frac{A R_{r} u_{s k}}{j \omega_{1}\left(j \omega_{s}+1 / T_{r}\right)} \\
& \left.-\frac{A R_{r}\left(u_{s 0}-u_{s k}\right)}{j \omega_{1}\left(-j \omega_{r}+1 / T_{r}-1 / T_{s}\right)} e^{-j \omega_{1} t} e^{-t / T_{s}}+C_{1} e^{-j \omega_{s} t} e^{-t / T_{r}}\right]=f\left(R_{s}, L_{s}, R_{r}, L_{r}, L_{m}, P_{s}, Q_{s}, u_{s k}, u_{s 0}, \omega_{1}, \omega_{s}, \omega_{r}\right) .
\end{aligned}
$$

2.2. Timer Action Crowbar. The crowbar circuit used in this paper is formed of a three-phase rectifier, power resistor, and series IGBT switch [21]. The crowbar protection signal is triggered when the magnitude of the rotor current exceeds a threshold value set for crowbar protection insertion (2 pu) and then remains engaged for a fixed time $(50 \mathrm{~ms})$. When the crowbar is released, rotor-side pulse width modulation (PWM) and rotor current PI control are immediately resumed. As shown in Figure 2, the DFIG wind turbine meets fault ride through requirements which refer to the capability 


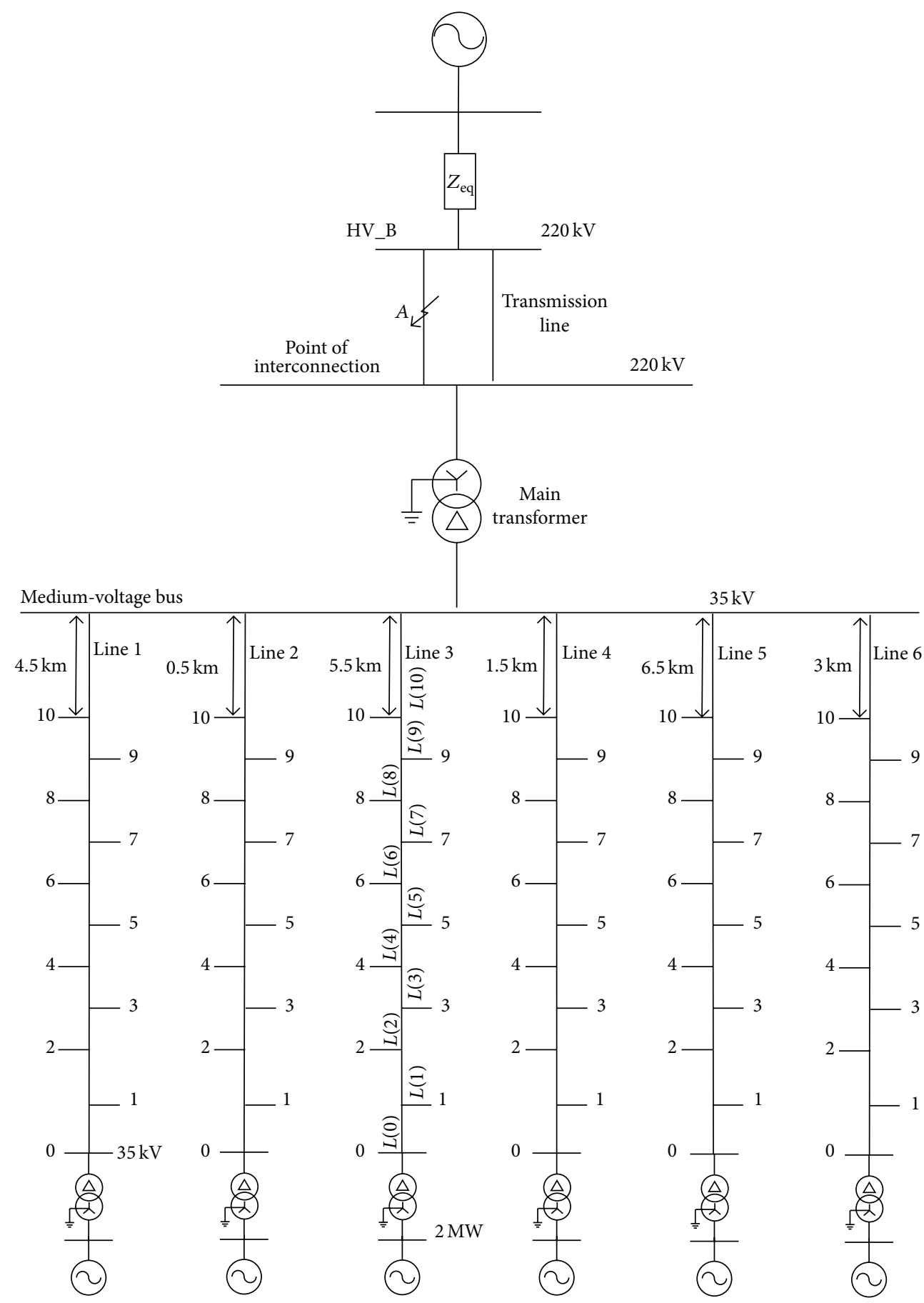

FIGURE 5: WPP network.

of generation plant to remain connected and dynamically stable and offer network support throughout a serious voltage disturbance [22].

2.3. Terminal Voltage Dip Threshold. According to (6), when the DFIG is connected to the infinite grid, the postfault rotor current is jointly determined by the generator parameters, active and reactive power outputs, terminal voltage dip, steady-state terminal voltage, and generator speed. For the DFIG with the MPPT property, there is a corresponding relationship between the generator speed and the active power output. Thus, the influence of the generator speed on the rotor current can be included in the influence of the active power output. Once the generator parameters and the maximum rotor current for crowbar protection insertion are 
TABLE 2: Wind data of each DFIG at $10.5 \mathrm{~m} / \mathrm{s}, 0.5^{\circ}$ wind.

\begin{tabular}{|c|c|}
\hline DFIG & $\mathrm{v} / \mathrm{m} \cdot \mathrm{s}^{-1}$ \\
\hline $1(0)$ & 10.50 \\
\hline 1(1) & 8.92 \\
\hline $1(2)$ & 8.38 \\
\hline 1(3) & 8.73 \\
\hline 1(4) & 8.18 \\
\hline 1(5) & 7.98 \\
\hline 1(6) & 7.92 \\
\hline 1(7) & 9.16 \\
\hline 1(8) & 8.59 \\
\hline 1(9) & 8.17 \\
\hline $1(10)$ & 8.04 \\
\hline $2(0)$ & 8.00 \\
\hline 2(1) & 7.99 \\
\hline $2(2)$ & 8.46 \\
\hline 2(3) & 8.25 \\
\hline $2(4)$ & 8.48 \\
\hline 2(5) & 8.46 \\
\hline 2(6) & 8.09 \\
\hline 2(7) & 8.00 \\
\hline $2(8)$ & 7.98 \\
\hline 2(9) & 8.46 \\
\hline 2(10) & 8.08 \\
\hline $3(0)$ & 10.50 \\
\hline $3(1)$ & 9.91 \\
\hline $3(2)$ & 8.57 \\
\hline 3(3) & 8.23 \\
\hline $3(4)$ & 8.14 \\
\hline 3(5) & 8.77 \\
\hline $3(6)$ & 8.11 \\
\hline 3(7) & 10.32 \\
\hline $3(8)$ & 8.85 \\
\hline 3(9) & 8.99 \\
\hline 3(10) & 8.66 \\
\hline $4(0)$ & 8.20 \\
\hline $4(1)$ & 7.99 \\
\hline $4(2)$ & 7.98 \\
\hline $4(3)$ & 7.97 \\
\hline $4(4)$ & 7.97 \\
\hline 4(5) & 7.97 \\
\hline $4(6)$ & 7.96 \\
\hline $4(7)$ & 7.96 \\
\hline $4(8)$ & 7.96 \\
\hline $4(9)$ & 7.96 \\
\hline 4(10) & 7.96 \\
\hline $5(0)$ & 10.50 \\
\hline
\end{tabular}

TABle 2: Continued.

\begin{tabular}{lc}
\hline DFIG & $\mathrm{v} / \mathrm{m} \cdot \mathrm{s}^{-1}$ \\
\hline $5(1)$ & 8.74 \\
$5(2)$ & 8.32 \\
$5(3)$ & 8.15 \\
$5(4)$ & 8.20 \\
$5(5)$ & 8.84 \\
$5(6)$ & 8.25 \\
$5(7)$ & 8.16 \\
$5(8)$ & 8.63 \\
$5(9)$ & 8.78 \\
$5(10)$ & 8.06 \\
$6(0)$ & 9.04 \\
$6(1)$ & 9.68 \\
$6(2)$ & 8.61 \\
$6(3)$ & 8.35 \\
$6(4)$ & 8.06 \\
$6(5)$ & 9.34 \\
$6(6)$ & 9.02 \\
$6(7)$ & 8.93 \\
$6(8)$ & 8.28 \\
$6(9)$ & 8.08 \\
$6(10)$ & 8.01 \\
\hline
\end{tabular}

fixed, the terminal voltage dip is the function of only the power outputs and the steady-state terminal voltage. As a result, the terminal voltage dip threshold can be quantified when the crowbar protection is just activated. Crowbar conduction occurs if the terminal voltage dip is lower than the terminal voltage drop threshold. Otherwise, the crowbar protection is not activated.

We select $0.1 \mathrm{MW}$ as the power step length within the scope of the DFIG rated power and $0.01 \mathrm{pu}$ as the voltage step length within the amplitude scope of steady-state terminal voltage $0.97-1.07 \mathrm{pu}$ [22]. The terminal voltage dip changes through regulating the external short-circuit impedance and then finding out the terminal voltage dip threshold which makes the rotor current equal to the maximum rotor current for crowbar protection insertion. The terminal voltage dip thresholds of the DFIG whose power factor is $-0.95,1$, and 0.95 , respectively, are presented in Figure 3. The DFIG parameters are specified in Table 1.

\section{Dynamic Equivalence of the WPP}

3.1. Effect of Collector Line Impedance on Terminal Voltage Dip Threshold. In order to reduce the power loss of a low-voltage circuit, it might be a better practice to connect multiple wind turbines to a middle-voltage bus using the daisy-chain structure within an actual WPP and then power in-feed to the external grid from the WPP through transmission lines. In the same feeder, owing to the convergence effect of output 


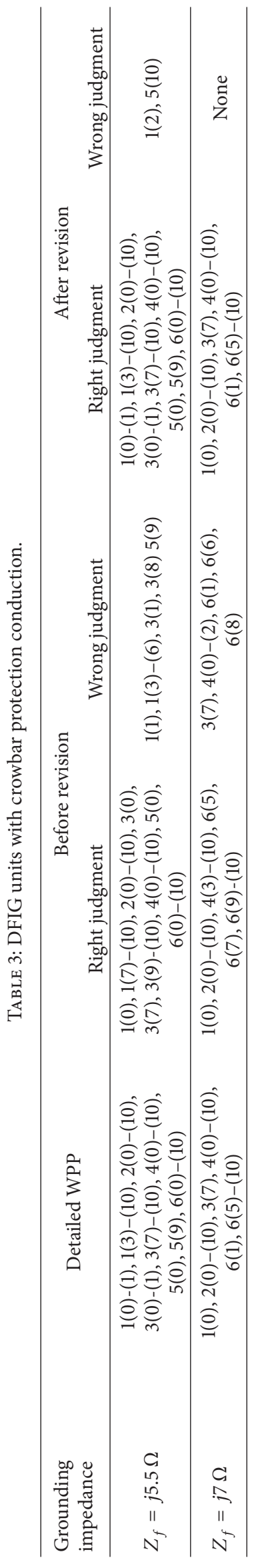


TABLE 4: Wind data of each DFIG at $8.5 \mathrm{~m} / \mathrm{s}, 174.5^{\circ}$ wind.

\begin{tabular}{|c|c|}
\hline DFIG & $\mathrm{v} / \mathrm{m}^{-1}$ \\
\hline $1(0)$ & 6.36 \\
\hline 1(1) & 6.23 \\
\hline $1(2)$ & 7.44 \\
\hline 1(3) & 6.29 \\
\hline $1(4)$ & 6.93 \\
\hline 1(5) & 6.92 \\
\hline 1(6) & 7.45 \\
\hline $1(7)$ & 6.38 \\
\hline $1(8)$ & 6.40 \\
\hline $1(9)$ & 6.46 \\
\hline $1(10)$ & 6.99 \\
\hline $2(0)$ & 6.39 \\
\hline $2(1)$ & 7.64 \\
\hline $2(2)$ & 6.37 \\
\hline 2(3) & 6.37 \\
\hline $2(4)$ & 6.40 \\
\hline $2(5)$ & 6.65 \\
\hline $2(6)$ & 7.00 \\
\hline $2(7)$ & 6.50 \\
\hline $2(8)$ & 6.83 \\
\hline $2(9)$ & 8.50 \\
\hline $2(10)$ & 8.26 \\
\hline $3(0)$ & 6.39 \\
\hline $3(1)$ & 6.64 \\
\hline $3(2)$ & 7.11 \\
\hline $3(3)$ & 6.28 \\
\hline $3(4)$ & 7.05 \\
\hline $3(5)$ & 7.58 \\
\hline $3(6)$ & 6.79 \\
\hline $3(7)$ & 8.16 \\
\hline $3(8)$ & 6.58 \\
\hline $3(9)$ & 7.70 \\
\hline $3(10)$ & 6.36 \\
\hline $4(0)$ & 6.36 \\
\hline $4(1)$ & 6.36 \\
\hline $4(2)$ & 6.37 \\
\hline $4(3)$ & 6.37 \\
\hline $4(4)$ & 6.38 \\
\hline $4(5)$ & 6.39 \\
\hline $4(6)$ & 6.42 \\
\hline $4(7)$ & 6.49 \\
\hline $4(8)$ & 6.83 \\
\hline $4(9)$ & 8.50 \\
\hline $4(10)$ & 6.16 \\
\hline $5(0)$ & 6.40 \\
\hline $5(1)$ & 6.47 \\
\hline
\end{tabular}

TABLE 4: Continued.

\begin{tabular}{lc}
\hline DFIG & $\mathrm{v} / \mathrm{m} \cdot \mathrm{s}^{-1}$ \\
\hline $5(2)$ & 7.13 \\
$5(3)$ & 6.36 \\
$5(4)$ & 6.39 \\
$5(5)$ & 6.49 \\
$5(6)$ & 6.50 \\
$5(7)$ & 7.86 \\
$5(8)$ & 6.35 \\
$5(9)$ & 6.39 \\
$5(10)$ & 6.52 \\
$6(0)$ & 7.72 \\
$6(1)$ & 6.40 \\
$6(2)$ & 7.21 \\
$6(3)$ & 7.02 \\
$6(4)$ & 8.14 \\
$6(5)$ & 6.47 \\
$6(6)$ & 6.39 \\
$6(7)$ & 6.42 \\
$6(8)$ & 6.49 \\
$6(9)$ & 6.83 \\
$6(10)$ & 8.50 \\
\hline
\end{tabular}

current from other wind turbines, the voltage delta between a wind turbine and the middle-voltage bus has increased significantly, which is equivalent to increasing the electrical distance of the wind turbine to the middle-voltage bus.

Within the WPP, the differences in terminal voltages among the wind turbines are mainly caused by the different electrical distances from each wind turbine to the middlevoltage bus. Compared with the infinite grid connection structure for a single DFIG, in the WPP topology, the increasing effect of electrical distance between the wind turbine and the middle-voltage bus means the line impedance must not be ignored. At this time, the line impedance is jointed between the grounding transformer and the middle-voltage bus. Based on (6), if the impedance is incorporated into the generator stator side, the change in generator impedance parameters will have an impact on the rotor time constant, which will affect the relationship between the terminal voltage dip and rotor current. Therefore, the terminal voltage dip thresholds should be revised.

3.2. Terminal Voltage Dip Threshold Revision. In the same feeder, owing to the convergence of output currents among the wind turbines, the voltage drop has increased. In this paper, the virtual line impedance is introduced to characterize the equivalent electrical distance in the daisychain topological structure of the WPP. 
TABLE 5: Equivalent accuracy of crowbar conduction and model error indices.

\begin{tabular}{|c|c|c|c|c|c|c|c|c|}
\hline \multirow{2}{*}{ Operating conditions } & \multirow{2}{*}{ Clustering index } & \multirow{2}{*}{ Equivalent accuracy/\% } & \multicolumn{3}{|c|}{ Dynamic absolute error } & \multicolumn{3}{|c|}{ Dynamic relative error } \\
\hline & & & $U / \mathrm{pu}$ & $\mathrm{P} / \mathrm{MW}$ & Q/Mvar & $U / \%$ & $P / \%$ & $\mathrm{Q} / \%$ \\
\hline \multirow{3}{*}{ Figure 6(a) } & Crowbar conduction & 100.0 & 0.0004 & 0.08 & 0.12 & 0.07 & 0.65 & 1.44 \\
\hline & Incoming wind & 77.3 & 0.0016 & 0.53 & 0.61 & 0.39 & 5.36 & 3.98 \\
\hline & Speed vector of generator & 57.6 & 0.0061 & 0.67 & 2.32 & 1.42 & 6.32 & 25.87 \\
\hline \multirow{3}{*}{ Figure 6(b) } & Crowbar conduction & 100.0 & 0.0007 & 0.10 & 0.23 & 0.15 & 0.77 & 16.03 \\
\hline & Incoming wind & 54.5 & 0.0046 & 0.73 & 1.78 & 1.13 & 6.39 & 27.44 \\
\hline & Speed vector of generator & 47.0 & 0.0072 & 0.56 & 2.62 & 1.66 & 4.74 & 236.25 \\
\hline \multirow{3}{*}{ Figure 6(c) } & Crowbar conduction & 98.5 & 0.0012 & 0.35 & 0.50 & 0.22 & 2.46 & 3.78 \\
\hline & Incoming wind & 72.7 & 0.0035 & 0.35 & 1.25 & 0.79 & 2.22 & 13.74 \\
\hline & Speed vector of generator & 72.7 & 0.0045 & 0.57 & 1.78 & 0.95 & 3.59 & 16.72 \\
\hline \multirow{3}{*}{ Figure 7(a) } & Crowbar conduction & 98.5 & 0.0005 & 0.10 & 0.21 & 0.13 & 6.74 & 1.88 \\
\hline & Incoming wind & 54.5 & 0.0044 & 0.81 & 1.55 & 1.21 & 74.75 & 21.31 \\
\hline & Speed vector of generator & 53.0 & 0.0042 & 0.85 & 1.46 & 1.16 & 73.81 & 19.85 \\
\hline \multirow{3}{*}{ Figure 7(b) } & Crowbar conduction & 95.5 & 0.0006 & 0.22 & 0.22 & 0.14 & 7.23 & 3.97 \\
\hline & Incoming wind & 50.0 & 0.0066 & 1.19 & 2.35 & 1.80 & 45.76 & 53.90 \\
\hline & Speed vector of generator & 51.5 & 0.0064 & 1.22 & 2.26 & 1.74 & 45.51 & 50.70 \\
\hline \multirow{3}{*}{ Figure $7(\mathrm{c})$} & Crowbar conduction & 100.0 & 0.0004 & 0.13 & 0.19 & 0.07 & 2.17 & 0.86 \\
\hline & Incoming wind & 80.3 & 0.0006 & 0.18 & 0.20 & 0.08 & 3.50 & 0.97 \\
\hline & Speed vector of generator & 78.8 & 0.0005 & 0.24 & 0.26 & 0.10 & 3.20 & 1.13 \\
\hline
\end{tabular}

As shown in Figure 4, there are n DFIGs in one feeder, and the voltage drop $\Delta U_{k}$ that is between the wind turbine number $k$ and the middle-voltage bus is

$$
\Delta U_{k}=\frac{\sum_{j=k}^{n}\left(Z_{j} \sum_{i=1}^{j} S_{i}^{*}\right)}{\sqrt{3} U},
$$

where $Z_{j}$ refers to the line impedance number $j ; S_{i}^{*}$ is the conjugate value of apparent power of the wind turbine number $i$; $U$ is the voltage amplitude of the middle-voltage bus.

Based on the principle of equal voltage drop, the virtual line impedance $Z_{\text {eq }-k}$ which is between the wind turbine number $k$ and the middle-voltage bus is

$$
Z_{\mathrm{eq}-k}=\frac{\sum_{j=k}^{n}\left(Z_{j} \sum_{i=1}^{j} S_{i}^{*}\right)}{S_{k}^{*}} .
$$

In the infinite grid connection structure for a single DFIG, $Z_{\text {eq- } k}$ is jointed into the grounding transformer and the middle-voltage bus; then, the terminal voltage dip threshold is redetermined by means of the method in Section 2.3.

3.3. Clustering Principle of DFIGs. Based on the coherencybased method in the power system dynamic equivalence, crowbar conduction is selected as the clustering principle; for example, DFIGs are divided into two groups: (1) crowbar conduction during the fault; (2) crowbar nonconduction during the fault. Depending on the abovementioned analysis, whether the crowbar protection is activated or not can be judged by comparing the postfault terminal voltage dip of the DFIG with its terminal voltage dip threshold.

\section{Simulation Results}

The developed equivalent WPP is tested by comparing its transient response with the traditional equivalent WPPs and the detailed WPP.

4.1. WPP Description. The network of the WPP is presented in Figure 5. The WPP is composed of one $35 / 220 \mathrm{kV}$ transformer, six collector systems, and $0.69 \mathrm{kV}$ DFIGs that are connected to the collector system through $0.69 / 35 \mathrm{kV}$ grounding transformers. Each collector system has 11 DFIGs, and the interval between two DFIGs within the same collector system is $400 \mathrm{~m}$. Model parameters are given in Table 1.

4.2. Validation of Clustering Index. The measured wind data of the 66 DFIGs are listed in Table 2. All DFIGs operate with a unity power factor. Three-phase short-circuit faults are applied at point A, as shown in Figure 4. Faults start at $0.1 \mathrm{~s}$ and last for $150 \mathrm{~ms}$. Two case studies are performed for different short-circuit grounding impedance: (1) $Z_{f}=$ 
TABLE 6: The crowbar conditions of the detailed WPPs ( $\sqrt{ }$ stands for having a working crowbar).

\begin{tabular}{|c|c|c|c|c|c|c|c|}
\hline DFIG & Figure $6(a)$ & Figure 6(b) & Figure 6(c) & Figure $7(\mathrm{a})$ & Figure 7(b) & Figure $7(\mathrm{c})$ & Figure 8 \\
\hline 1(0) & & $\sqrt{ }$ & $\sqrt{ }$ & & & & $\sqrt{ }$ \\
\hline $1(1)$ & & & $\sqrt{ }$ & & & & $\sqrt{ }$ \\
\hline $1(2)$ & & & & & & & $\sqrt{ }$ \\
\hline $1(3)$ & & & $\sqrt{ }$ & & & & $\sqrt{ }$ \\
\hline $1(4)$ & & & & & & & $\sqrt{ }$ \\
\hline $1(5)$ & & & & & & & $\sqrt{ }$ \\
\hline $1(6)$ & & & & & & & $\sqrt{ }$ \\
\hline $1(7)$ & & & $\sqrt{ }$ & & & & $\sqrt{ }$ \\
\hline $1(8)$ & & & $\sqrt{ }$ & & & & $\sqrt{ }$ \\
\hline 1(9) & & & $\sqrt{ }$ & & $\sqrt{ }$ & & $\sqrt{ }$ \\
\hline $1(10)$ & & & $\sqrt{ }$ & & $\sqrt{ }$ & & $\sqrt{ }$ \\
\hline $2(0)$ & $\sqrt{ }$ & $\sqrt{ }$ & $\sqrt{ }$ & $\sqrt{ }$ & $\sqrt{ }$ & & $\sqrt{ }$ \\
\hline $2(1)$ & $\sqrt{ }$ & $\sqrt{ }$ & $\sqrt{ }$ & $\sqrt{ }$ & $\sqrt{ }$ & $\sqrt{ }$ & $\sqrt{ }$ \\
\hline $2(2)$ & & $\sqrt{ }$ & $\sqrt{ }$ & $\sqrt{ }$ & $\sqrt{ }$ & & $\sqrt{ }$ \\
\hline $2(3)$ & $\sqrt{ }$ & $\sqrt{ }$ & $\sqrt{ }$ & $\sqrt{ }$ & $\sqrt{ }$ & & $\sqrt{ }$ \\
\hline $2(4)$ & $\sqrt{ }$ & $\sqrt{ }$ & $\sqrt{ }$ & $\sqrt{ }$ & $\sqrt{ }$ & & $\sqrt{ }$ \\
\hline $2(5)$ & $\sqrt{ }$ & $\sqrt{ }$ & $\sqrt{ }$ & $\sqrt{ }$ & $\sqrt{ }$ & $\sqrt{ }$ & $\sqrt{ }$ \\
\hline $2(6)$ & $\sqrt{ }$ & $\sqrt{ }$ & $\sqrt{ }$ & $\sqrt{ }$ & $\sqrt{ }$ & $\sqrt{ }$ & $\sqrt{ }$ \\
\hline $2(7)$ & $\sqrt{ }$ & $\sqrt{ }$ & $\sqrt{ }$ & $\sqrt{ }$ & $\sqrt{ }$ & $\sqrt{ }$ & $\sqrt{ }$ \\
\hline $2(8)$ & $\sqrt{ }$ & $\sqrt{ }$ & $\sqrt{ }$ & $\sqrt{ }$ & $\sqrt{ }$ & $\sqrt{ }$ & $\sqrt{ }$ \\
\hline $2(9)$ & $\sqrt{ }$ & $\sqrt{ }$ & $\sqrt{ }$ & $\sqrt{ }$ & $\sqrt{ }$ & $\sqrt{ }$ & $\sqrt{ }$ \\
\hline $2(10)$ & $\sqrt{ }$ & $\sqrt{ }$ & $\sqrt{ }$ & $\sqrt{ }$ & $\sqrt{ }$ & $\sqrt{ }$ & $\sqrt{ }$ \\
\hline $3(0)$ & & & $\sqrt{ }$ & & & & \\
\hline $3(1)$ & & & $\sqrt{ }$ & & & & \\
\hline \multicolumn{8}{|l|}{$3(2)$} \\
\hline \multicolumn{8}{|l|}{$3(3)$} \\
\hline \multicolumn{8}{|l|}{$3(4)$} \\
\hline \multicolumn{8}{|l|}{$3(5)$} \\
\hline \multicolumn{8}{|l|}{$3(6)$} \\
\hline $3(7)$ & & $\sqrt{ }$ & $\sqrt{ }$ & & & & $\sqrt{ }$ \\
\hline $3(8)$ & & & $\sqrt{ }$ & & & & \\
\hline $3(9)$ & & & $\sqrt{ }$ & & & & $\sqrt{ }$ \\
\hline $3(10)$ & & & $\sqrt{ }$ & & & & $\sqrt{ }$ \\
\hline $4(0)$ & & $\sqrt{ }$ & $\sqrt{ }$ & $\sqrt{ }$ & $\sqrt{ }$ & & $\sqrt{ }$ \\
\hline $4(1)$ & & $\sqrt{ }$ & $\sqrt{ }$ & $\sqrt{ }$ & $\sqrt{ }$ & & $\sqrt{ }$ \\
\hline $4(2)$ & & $\sqrt{ }$ & $\sqrt{ }$ & $\sqrt{ }$ & $\sqrt{ }$ & & $\sqrt{ }$ \\
\hline $4(3)$ & & $\sqrt{ }$ & $\sqrt{ }$ & $\sqrt{ }$ & $\sqrt{ }$ & & $\sqrt{ }$ \\
\hline $4(4)$ & & $\sqrt{ }$ & $\sqrt{ }$ & $\sqrt{ }$ & $\sqrt{ }$ & & $\sqrt{ }$ \\
\hline $4(5)$ & & $\sqrt{ }$ & $\sqrt{ }$ & $\sqrt{ }$ & $\sqrt{ }$ & & $\sqrt{ }$ \\
\hline $4(6)$ & $\sqrt{ }$ & $\sqrt{ }$ & $\sqrt{ }$ & $\sqrt{ }$ & $\sqrt{ }$ & & $\sqrt{ }$ \\
\hline $4(7)$ & $\sqrt{ }$ & $\sqrt{ }$ & $\sqrt{ }$ & $\sqrt{ }$ & $\sqrt{ }$ & & $\sqrt{ }$ \\
\hline $4(8)$ & $\sqrt{ }$ & $\sqrt{ }$ & $\sqrt{ }$ & $\sqrt{ }$ & $\sqrt{ }$ & $\sqrt{ }$ & $\sqrt{ }$ \\
\hline $4(9)$ & $\sqrt{ }$ & $\sqrt{ }$ & $\sqrt{ }$ & $\sqrt{ }$ & $\sqrt{ }$ & $\sqrt{ }$ & $\sqrt{ }$ \\
\hline
\end{tabular}


TABLe 6: Continued.

\begin{tabular}{|c|c|c|c|c|c|c|c|}
\hline DFIG & Figure 6(a) & Figure 6(b) & Figure 6(c) & Figure $7(\mathrm{a})$ & Figure $7(b)$ & Figure $7(\mathrm{c})$ & Figure 8 \\
\hline $4(10)$ & $\sqrt{ }$ & $\sqrt{ }$ & $\sqrt{ }$ & $\sqrt{ }$ & $\sqrt{ }$ & $\sqrt{ }$ & $\sqrt{ }$ \\
\hline $5(0)$ & & & $\sqrt{ }$ & & & & \\
\hline $5(1)$ & & & & & & & \\
\hline $5(2)$ & & & & & & & \\
\hline $5(3)$ & & & & & & & \\
\hline $5(4)$ & & & & & & & \\
\hline $5(5)$ & & & & & & & \\
\hline $5(6)$ & & & & & & & \\
\hline $5(7)$ & & & & & & & \\
\hline $5(8)$ & & & & & & & \\
\hline $5(9)$ & & & $\sqrt{ }$ & & & & \\
\hline $5(10)$ & & & & & & & \\
\hline $6(0)$ & & & $\sqrt{ }$ & & $\sqrt{ }$ & & \\
\hline $6(1)$ & & $\sqrt{ }$ & $\sqrt{ }$ & & & & \\
\hline $6(2)$ & & & $\sqrt{ }$ & & $\sqrt{ }$ & & \\
\hline $6(3)$ & & & $\sqrt{ }$ & & $\sqrt{ }$ & & \\
\hline $6(4)$ & & & $\sqrt{ }$ & & $\sqrt{ }$ & $\sqrt{ }$ & \\
\hline $6(5)$ & & $\sqrt{ }$ & $\sqrt{ }$ & & $\sqrt{ }$ & & \\
\hline $6(6)$ & & $\sqrt{ }$ & $\sqrt{ }$ & & $\sqrt{ }$ & & \\
\hline $6(7)$ & & $\sqrt{ }$ & $\sqrt{ }$ & $\sqrt{ }$ & $\sqrt{ }$ & & \\
\hline $6(8)$ & & $\sqrt{ }$ & $\sqrt{ }$ & $\sqrt{ }$ & $\sqrt{ }$ & & \\
\hline $6(9)$ & & $\sqrt{ }$ & $\sqrt{ }$ & $\sqrt{ }$ & $\sqrt{ }$ & & \\
\hline $6(10)$ & & $\sqrt{ }$ & $\sqrt{ }$ & $\sqrt{ }$ & $\sqrt{ }$ & $\sqrt{ }$ & \\
\hline
\end{tabular}

TABLE 7: Equivalent accuracy of crowbar conduction and model error indices.

\begin{tabular}{lccccccc}
\hline \multirow{2}{*}{ Clustering index } & \multirow{2}{*}{ Equivalent accuracy/\% } & \multicolumn{3}{c}{ Dynamic absolute error } & \multicolumn{3}{c}{ Dynamic relative error } \\
& & $U / \mathrm{pu}$ & $P / \mathrm{MW}$ & $\mathrm{Q} / \mathrm{Mvar}$ & $U / \%$ & $P / \%$ & $\mathrm{Q} / \%$ \\
\hline Crowbar conduction & 98.5 & 0.0014 & 0.17 & 0.55 & 0.29 & 1.34 & 11.06 \\
Incoming wind & 56.1 & 0.0057 & 0.48 & 1.89 & 1.41 & 3.61 & 41.82 \\
Speed vector of generator & 56.1 & 0.0055 & 0.43 & 1.82 & 1.38 & 3.24 & 39.86 \\
Reactive-power level & 89.4 & 0.0061 & 0.28 & 1.22 & 1.32 & 2.44 & 57.48 \\
\hline
\end{tabular}

$j 5.5 \Omega$; (2) $Z_{f}=j 7 \Omega$; therefore, the voltage of the $35 \mathrm{kV}$ bus decreases to $53.7 \%$ and $55.7 \%$ of its nominal value. The postfault terminal voltage of the DFIG is compared with its terminal voltage dip threshold before revision and after revision, respectively, thus judging the DFIG whose crowbar protection is activated. Then, based on the simulation results of the detailed WPP, the correctness of the abovementioned judgment is tested, and the statistical results are listed in Table 3.

As can be seen from Table 3, when $Z_{f}=j 5.5 \Omega$ and $Z_{f}=j 7 \Omega$, based on the terminal voltage dip threshold before revision, the numbers of wrong judgments of crowbar conduction are eight and seven, respectively; based on the terminal voltage dip threshold after revision, the numbers of wrong judgments of crowbar conduction are reduced to two and zero, respectively. The accuracy of the judgment of crowbar protection conduction can be significantly improved by using the terminal voltage dip threshold after revision.

4.3. Transient Response. The detailed WPP and the equivalent WPPs are modeled on the DIgSILENT PowerFactory platform. The detailed WPP consists of the 66 DFIGs, collection systems, grounding transformers, and a main transformer. Three-phase short-circuit faults are applied at point A, as shown in Figure 5. Faults start at $0.1 \mathrm{~s}$ and last for $150 \mathrm{~ms}$. 

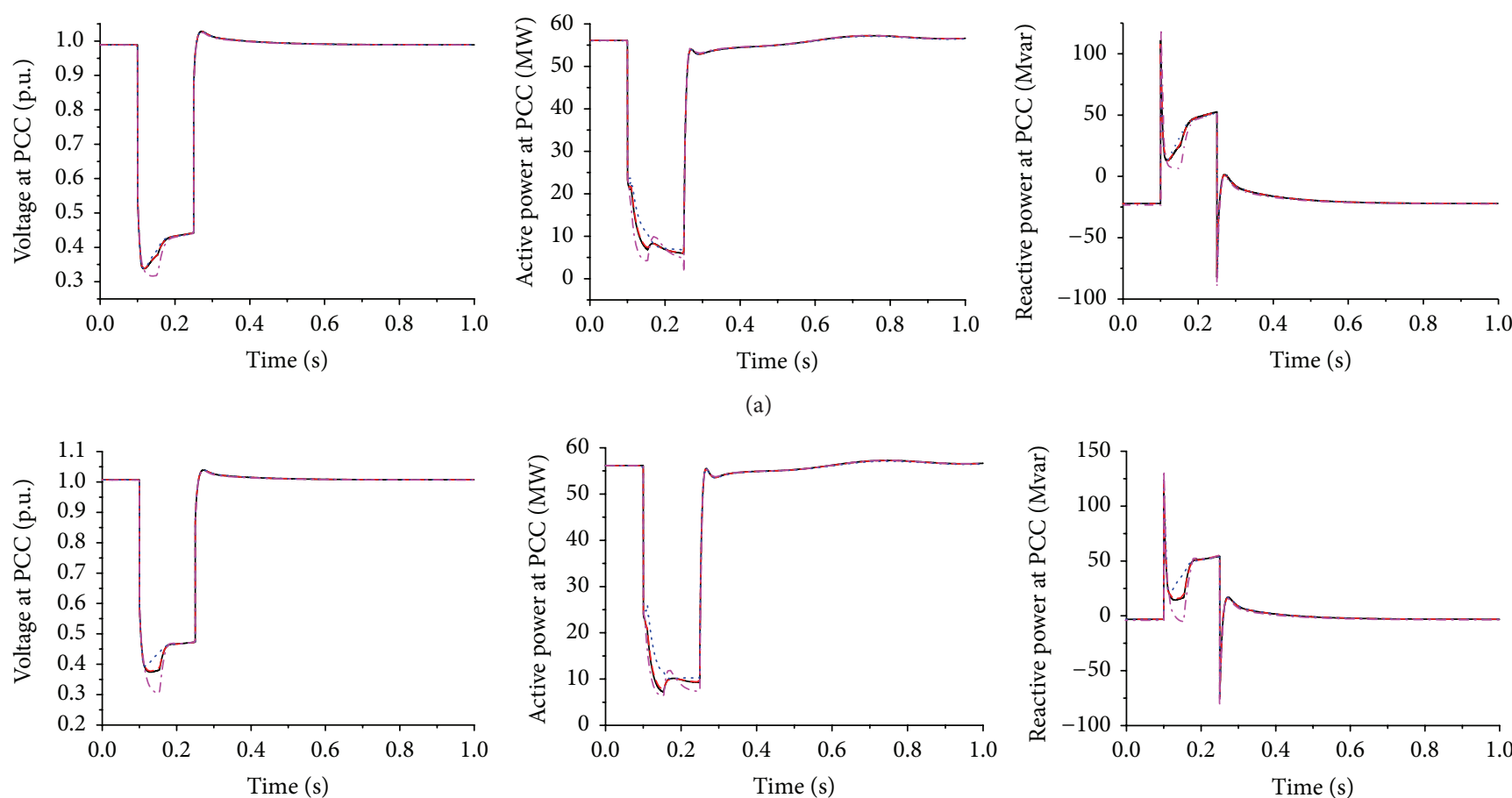

(a)
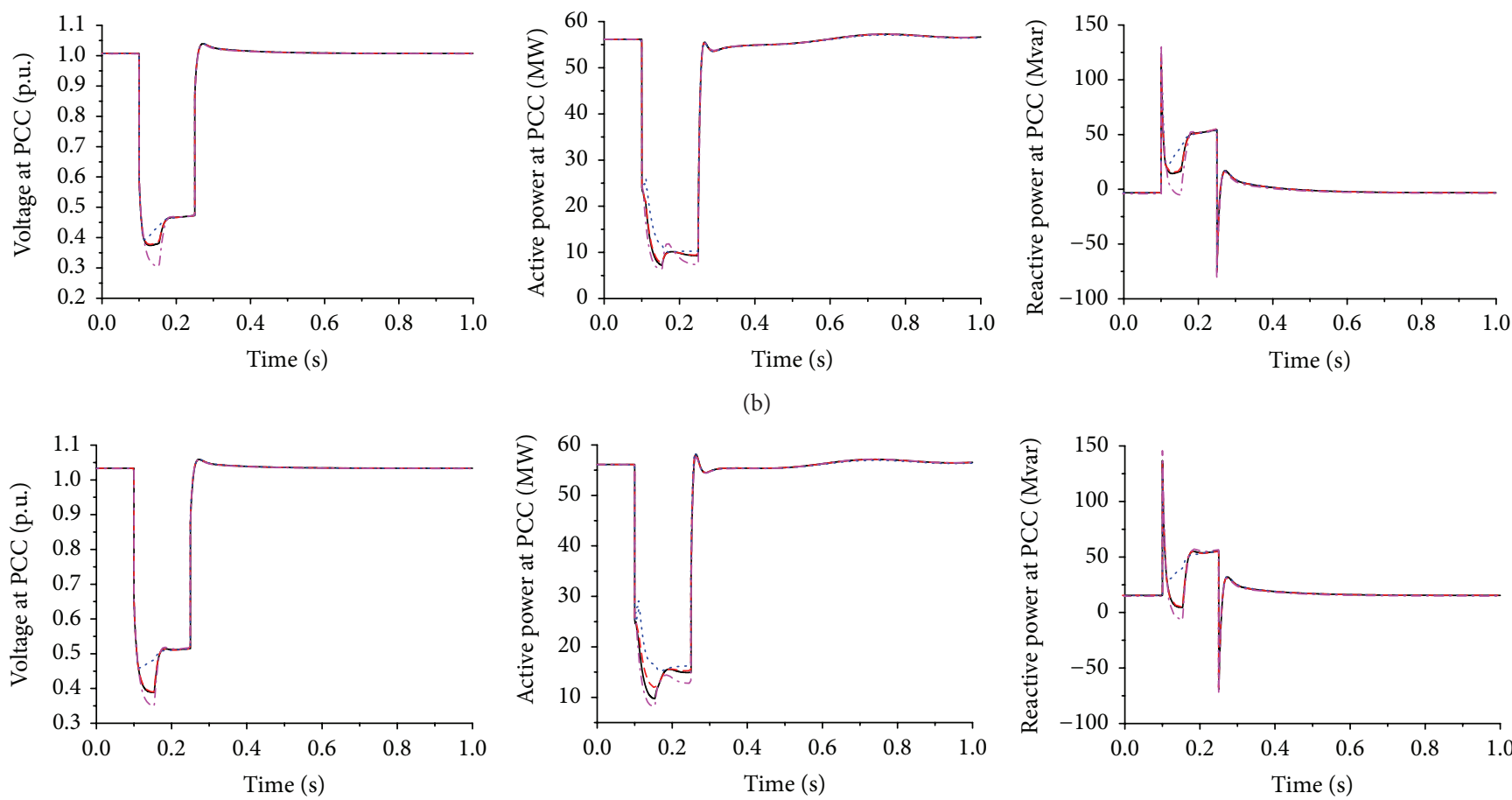

(b)
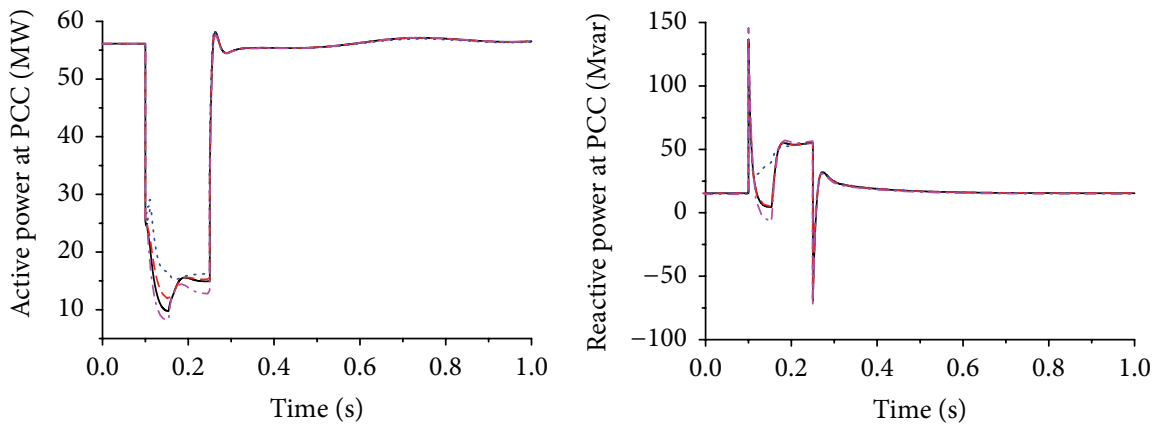

(c)

Figure 6: $U, P$, and $Q$ of the WPPs at $10.5 \mathrm{~m} / \mathrm{s}, 0.5^{\circ}$ wind: (a) power factor $=-0.95$, (b) power factor $=1$, and (c) power factor $=0.95$. The three equivalent WPPs built based on crowbar conduction, incoming wind, and speed vector of generator are in red dash, blue dot, and magenta dash dot, respectively, and the detailed WPP is in black solid.

Compared with the simulation results of the detailed WPP, error indicators are defined as follows:

$$
\begin{aligned}
& E_{a}=\frac{1}{n} \sum_{i=1}^{n}\left|Y_{f i}(k)-Y_{i}(k)\right|, \\
& E_{r}=\frac{1}{n} \sum_{i=1}^{n}\left|\frac{Y_{f i}(k)-Y_{i}(k)}{Y_{i}(k)}\right|,
\end{aligned}
$$

where $Y_{i}(k)$ and $Y_{f i}(k)$ are the output variables of the complete collector system for the equivalent WPPs and the detailed WPP, respectively, and $n$ stands for the number of DFIGs within the WPP.

4.3.1. The Same Power Factor within WPP. All DFIGs operate with the same power factor, and two case studies are performed for different incoming winds: (1) $10.5 \mathrm{~m} / \mathrm{s}, 0.5^{\circ}$;
(2) $8.5 \mathrm{~m} / \mathrm{s}, 174.5^{\circ}$. Based on wake effects, the incoming winds of each DFIG are listed in Tables 2 and 4, respectively. Three different reactive-power levels of DFIG, for example, the maximum production (0.95), unity power factor, and maximum consumption (-0.95), are used for the cases. Figures 6 and 7 illustrate the behavior of the voltages, active and reactive powers of the complete collector system for the three equivalent WPPs, and the detailed WPP following the application of a three-phase short-circuit fault.

The equivalent accuracy of the equivalent WPPs compared to the detailed WPP about the crowbar protection conduction and error indices are listed in Table 5. During the fault, whether the crowbar protection is triggered or not decides the reactive power supporting ability of the DFIG to the power grid, thereby affecting the depth of the voltage dip and the active power output of the WPP. The equivalent WPP 

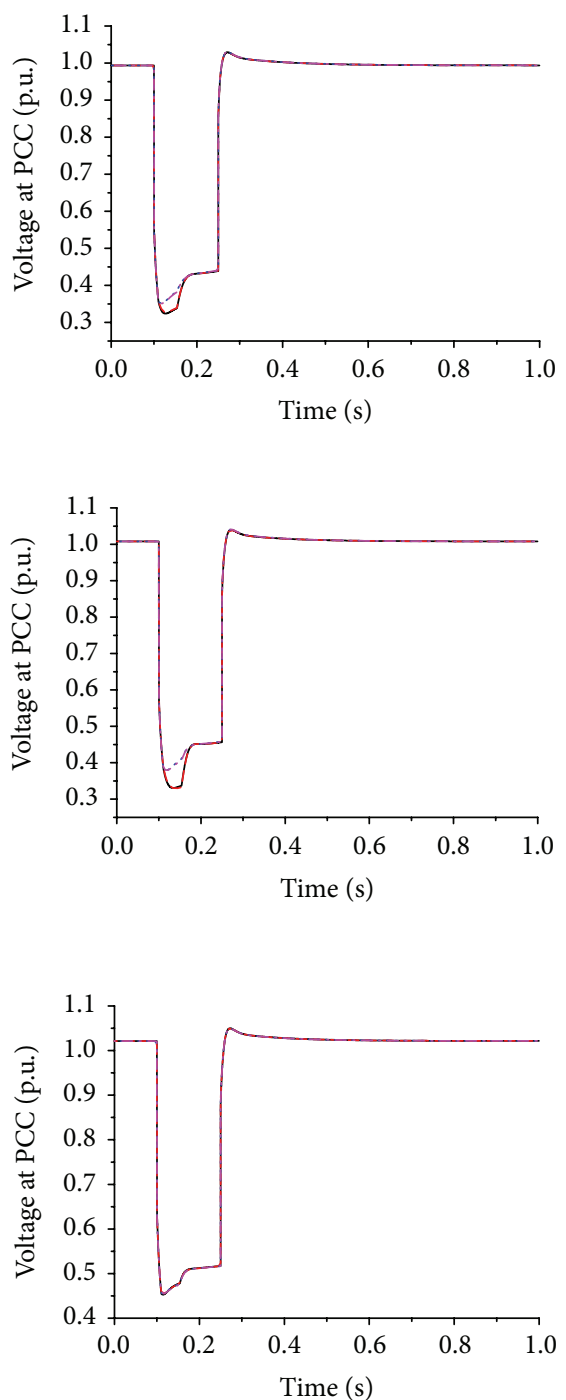

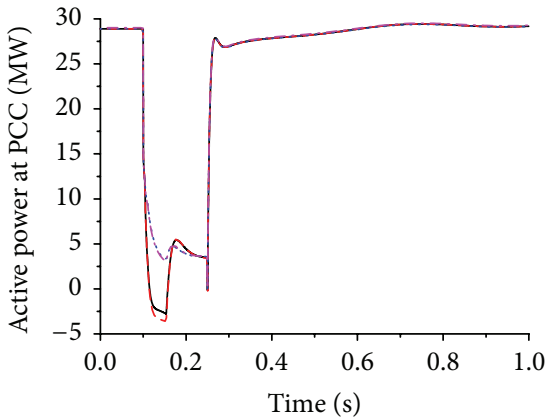

(a)

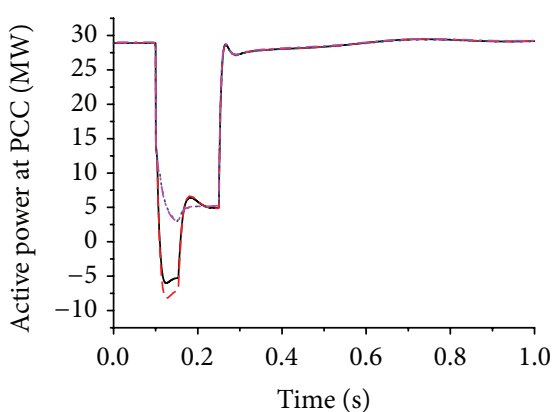

(b)

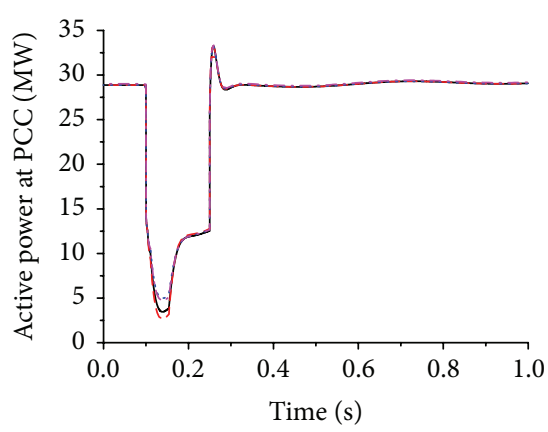

(c)
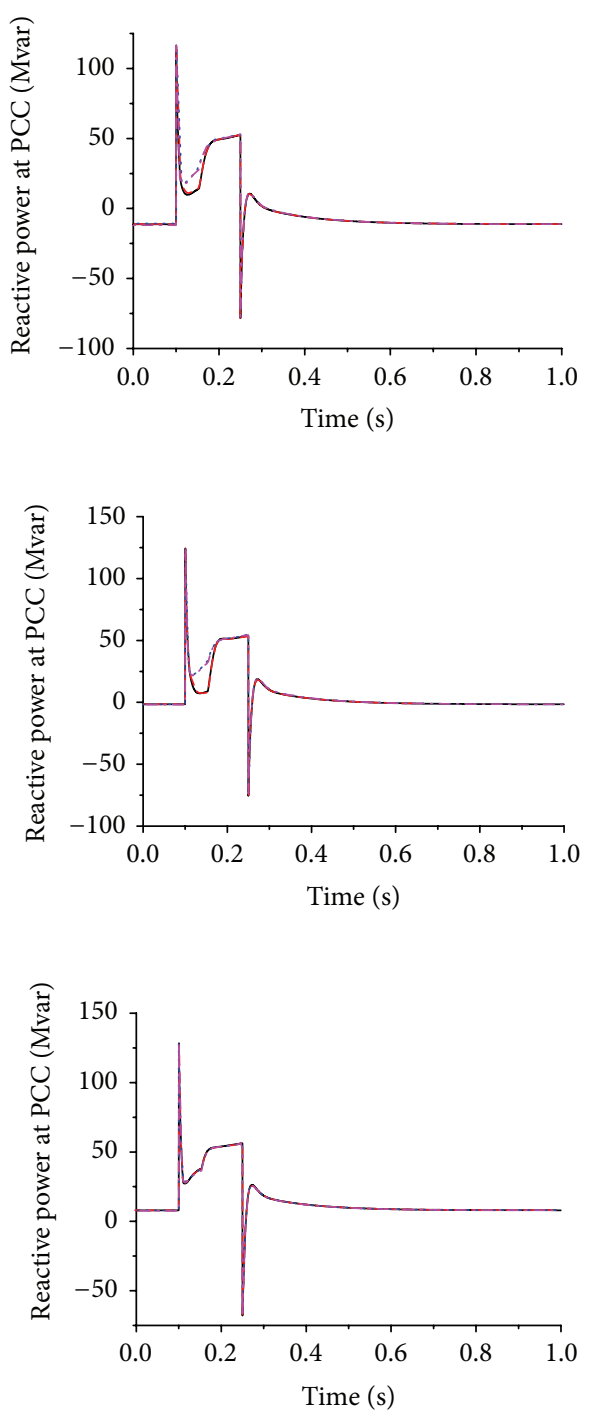

Figure 7: $U, P$, and $Q$ of the WPPs at $10.5 \mathrm{~m} / \mathrm{s}, 0.5^{\circ}$ wind: (a) power factor $=-0.95$, (b) power factor $=1$, and (c) power factor $=0.95$. The three equivalent WPPs built based on crowbar conduction, incoming wind, and speed vector of generator are in red dash, blue dot, and magenta dash dot, respectively, and the detailed WPP is in black solid.

built by this paper is more similar to the detailed WPP, due to its higher equivalent accuracy for crowbar conduction.

The crowbar conditions of the detailed WPPs are listed in Table 6. It should be noted that the DFIG might lose its capability to control the generator after crowbar conduction; thus, a DFIG whose generator speed is lower than the synchronous speed operates in the motor state. From fault elimination to crowbar protection resection, with the grid voltage recovery, a DFIG operating in the motor state will consume more active power, causing the active power at the complete collector system for the WPP to appear with a larger negative value. The equivalent WPP built by this paper can also accurately reflect this situation.

4.3.2. Different Power Factors among WPP Feeders. The incoming wind of the WPP is $10.5 \mathrm{~m} / \mathrm{s}, 0.5^{\circ}$. Based on wake effects, the incoming winds of each DFIG are listed in Table 2. The power factors of the DFIGs in feeders 1-2, 3-4, and $5-6$ are $-0.95,1$, and 0.95 , respectively. Three-phase shortcircuit faults are applied at point A, as shown in Figure 5. Faults start at $0.1 \mathrm{~s}$ and last for $150 \mathrm{~ms}$. Figure 8 shows the behavior of the active and reactive powers at the complete collector system for the equivalent WPPs and the detailed WPP following the application of a three-phase short-circuit fault. The crowbar condition of the detailed WPP is listed in Table 6. The equivalent accuracy of the equivalent WPPs compared to the detailed WPP about the crowbar protection conduction and error indices are listed in Table 7.

When the DFIGs operate with different power factors within the WPP, the traditional equivalent method will divide the DFIGs which have the same reactive-power level into groups. But the simulation results of the detailed WPP 

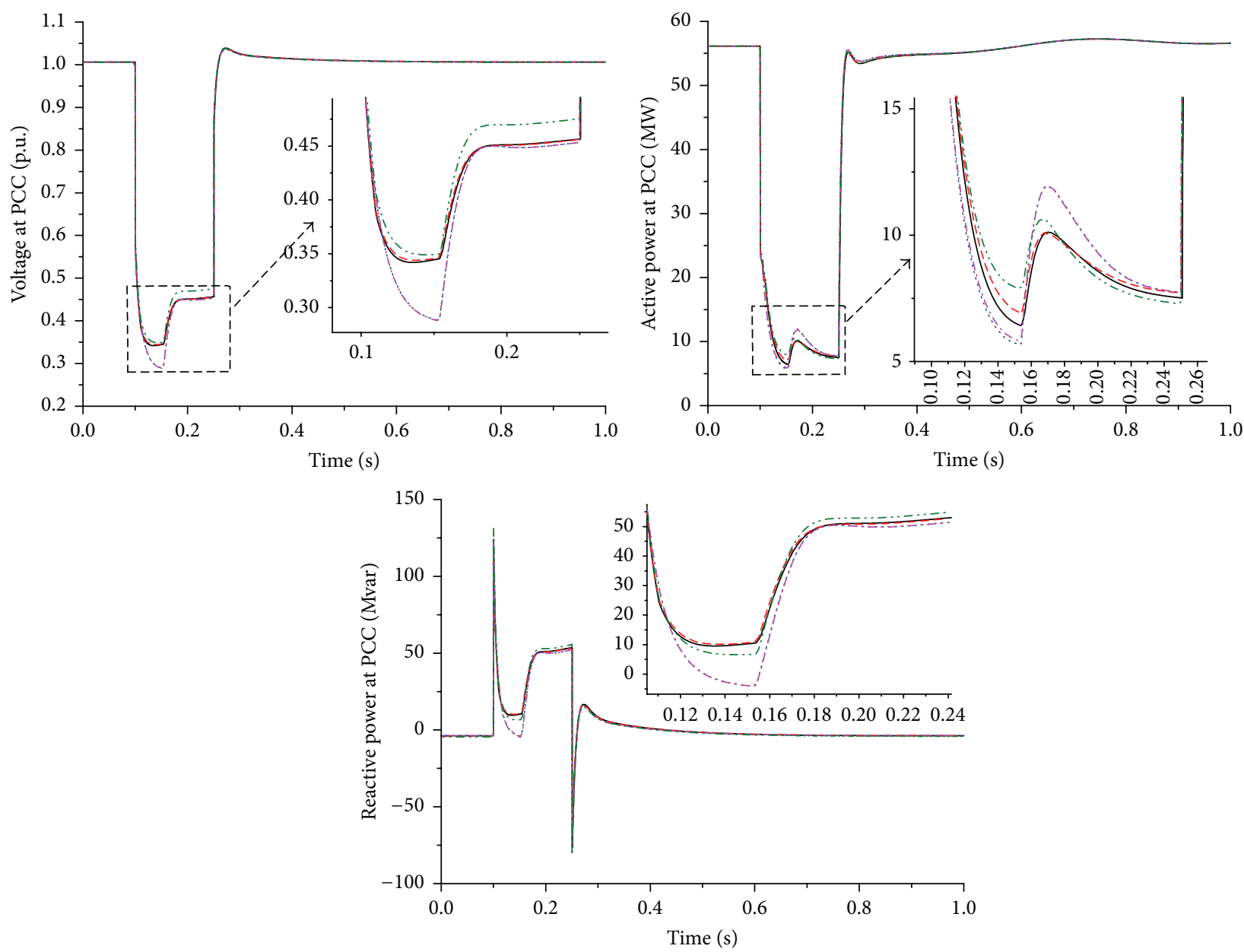

FIGURE 8: $U, P$, and $Q$ of the WPPs. The four equivalent WPPs built based on crowbar conduction, incoming wind, speed vector of generator, and reactive-power level are in red dash, blue dot, magenta dash dot, and green dash dot, respectively, and the detailed WPP is in black solid.

indicate that the crowbar conduction of DFIGs with the same power factor is not completely consistent.

\section{Conclusions}

After the fault, the crowbar conduction of the DFIG is related to the depth of the terminal voltage dip. This paper simplifies the judgment criterion of crowbar conduction as the terminal voltage dip threshold, which is convenient to calculate and makes it easy to identify the crowbar conduction.

Considering the influence of the connection line impedance within the same collector system on the terminal voltage dip threshold, the virtual line impedance is introduced to characterize the equivalent electrical distance from the DFIG to the medium-voltage bus. The equivalent accuracy of crowbar conduction discrimination is improved by revising the terminal voltage dip threshold.

The equivalent WPP established based on the division principle of crowbar conduction is verified, showing that it can more accurately reflect the external characteristics of the WPP.

\section{Appendix}

See Tables 1, 2, 4, and 6.

\section{Competing Interests}

The authors declare that there is no conflict of interests regarding the publication of this paper.

\section{Acknowledgments}

This work is supported by the National Natural Science Foundation of China (no. 51207039), the Science and Technology Foundation of SGCC (no. NY17201200073), and the National Energy Application Technology Research and Engineering Demonstration Projects (no. NY20110406-1).

\section{References}

[1] Z. Yu, M. E. Elbuluk, and Y. Sozer, "Stability analysis of maximum power point tracking (MPPT) method in wind 
power systems," IEEE Transactions on Industry Applications, vol. 49, no. 3, pp. 1129-1136, 2013.

[2] M. Tazil, V. Kumar, R. C. Bansal et al., "Three-phase doubly fed induction generators: an overview," IET Electric Power Applications, vol. 4, no. 2, pp. 75-89, 2010.

[3] J. López, P. Sanchis, X. Roboam, and L. Marroyo, "Dynamic behavior of the doubly fed induction generator during threephase voltage dips," IEEE Transactions on Energy Conversion, vol. 22, no. 3, pp. 709-717, 2007.

[4] E. Muljadi and A. Ellis, Final Project Report WECC Wind Generator Development, California Institute for Energy and Environment, 2010.

[5] M. A. Elizondo, L. Shuai, Z. Ning, and N. Samaan, "Model reduction, validation, and calibration of wind power plants for dynamic studies," in Proceedings of the IEEE Power and Energy Society General Meeting, pp. 1-8, San Diego, Calif, USA, July 2011.

[6] I. Erlich, F. Shewarega, C. Feltes, F. Koch, and J. Fortmann, "Determination of dynamic wind farm equivalents using heuristic optimization," in Proceedings of the IEEE Power and Energy Society General Meeting (PES '12), pp. 1-8, IEEE, San Diego, Calif, USA, July 2012.

[7] Y.-Q. Jin, P. Ju, and X.-P. Pan, "Analysis on controller aggregation method for equivalent modeling of DFIG-based wind farm," Automation of Electric Power Systems, vol. 38, no. 3, pp. 19-24, 2014.

[8] D. N. Hussein, M. Matar, and R. Iravani, "A type-4 wind power plant equivalent model for the analysis of electromagnetic transients in power systems," IEEE Transactions on Power Systems, vol. 28, no. 3, pp. 3096-3104, 2013.

[9] M. A. Chowdhury, W. X. Shen, N. Hosseinzadeh, and H. R. Pota, "A novel aggregated DFIG wind farm model using mechanical torque compensating factor," Energy Conversion and Management, vol. 67, pp. 265-274, 2013.

[10] L. M. Fernández, C. A. García, J. R. Saenz, and F. Jurado, "Equivalent models of wind farms by using aggregated wind turbines and equivalent winds," Energy Conversion and Management, vol. 50, no. 3, pp. 691-704, 2009.

[11] I. Zubia, J. X. Ostolaza, A. Susperregui, and J. J. Ugartemendia, "Multi-machine transient modelling of wind farms: an essential approach to the study of fault conditions in the distribution network," Applied Energy, vol. 89, no. 1, pp. 421-429, 2012.

[12] M. Ali, I.-S. Ilie, J. V. Milanovic, and G. Chicco, "Wind farm model aggregation using probabilistic clustering," IEEE Transactions on Power Systems, vol. 28, no. 1, pp. 309-316, 2013.

[13] E. Muljadi, C. P. Butterfield, A. Ellis et al., "Equivalencing the collector system of a large wind power plant," in Proceedings of the IEEE Power Engineering Society General Meeting (PES '06), pp. 1-9, Montreal, Canada, June 2006.

[14] Y. Cheng, M. Sahni, J. Conto, S.-H. Huang, and J. Schmall, "Voltage-profile-based approach for developing collection system aggregated models for wind generation resources for grid voltage ride-through studies," IET Renewable Power Generation, vol. 5, no. 5, pp. 332-346, 2011.

[15] Q. Zhu, P. Han, M. Ding, X. Zhang, and W. Shi, "Probabilistic equivalent model for wind farms based on clusteringdiscriminant analysis," Proceedings of the Chinese Society of Electrical Engineering, vol. 34, no. 28, pp. 4770-4780, 2014.

[16] E. Muljadi, Z. Mills, R. Foster, J. Conto, and A. Ellis, "Fault analysis at a wind power plant for one year observation," in Proceedings of the IEEE Power Energy Society General Meeting, pp. 1-7, Pittsburgh, Pa, USA, July 2008.
[17] Y. Zhang, E. Muljadi, D. Kosterev, and M. Singh, "Wind power plant model validation using synchrophasor measurements at the point of interconnection," IEEE Transactions on Sustainable Energy, vol. 6, no. 3, pp. 984-992, 2015.

[18] A. Perdana, S. Uski-Joutsenvuo, O. Carlson, and B. Lemström, "Comparison of an aggregated model of a wind farm consisting of fixed-speed wind turbines with field measurement," Wind Energy, vol. 11, no. 1, pp. 13-27, 2008.

[19] M. Singh, K. Faria, S. Santoso, and E. Muljadi, "Validation and analysis of wind power plant models using short-circuit field measurement data," in Proceedings of the IEEE Power \& Energy Society General Meeting (PES '09), pp. 1-6, Calgary, Canada, July 2009.

[20] J. Brochu, C. Larose, and R. Gagnon, "Validation of single- and multiple-machine equivalents for modeling wind power plants," IEEE Transactions on Energy Conversion, vol. 26, no. 2, pp. 532541, 2011.

[21] G. Pannell, D. J. Atkinson, and B. Zahawi, "Minimum-threshold crowbar for a fault-ride-through grid-code-compliant DFIG wind turbine," IEEE Transactions on Energy Conversion, vol. 25, no. 3, pp. 750-759, 2010.

[22] State Grid Corporation of China, Technology Rule for Connecting Wind Farm Into Power Grid, State Grid Corporation of China, Beijing, China, 2009. 


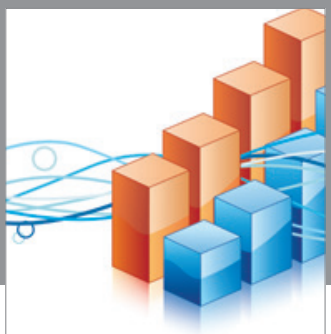

Advances in

Operations Research

vatem alat4

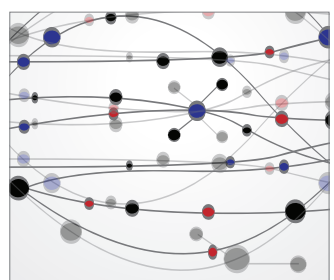

\section{The Scientific} World Journal
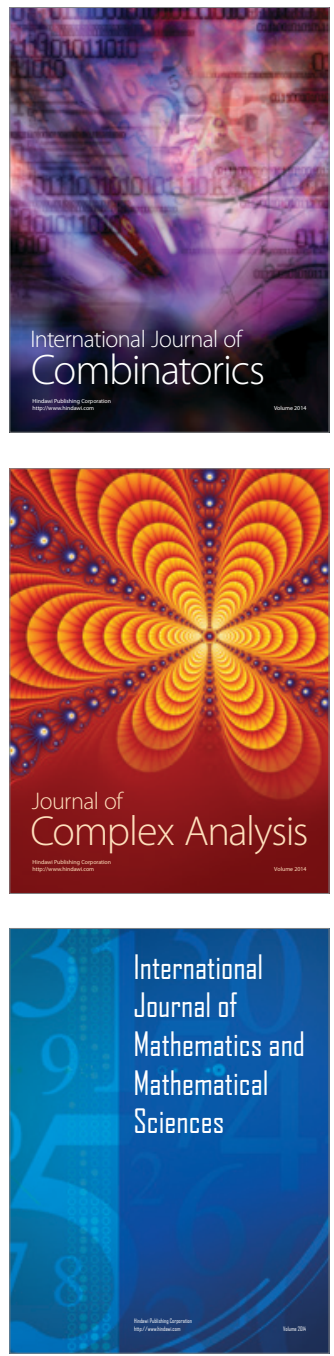
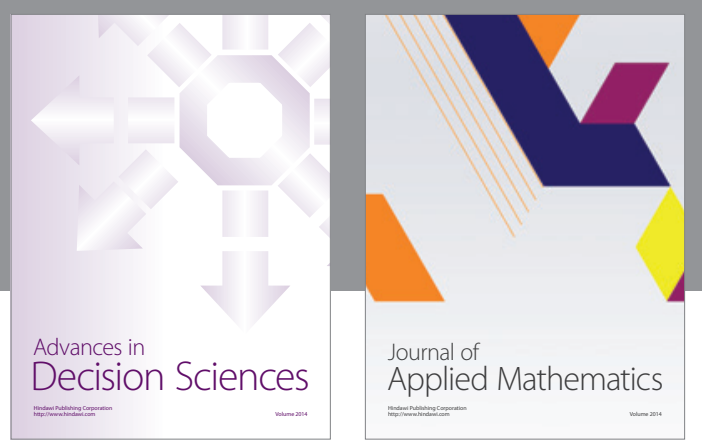

Algebra

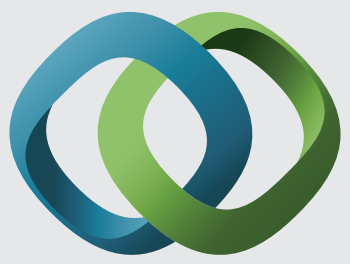

\section{Hindawi}

Submit your manuscripts at

http://www.hindawi.com
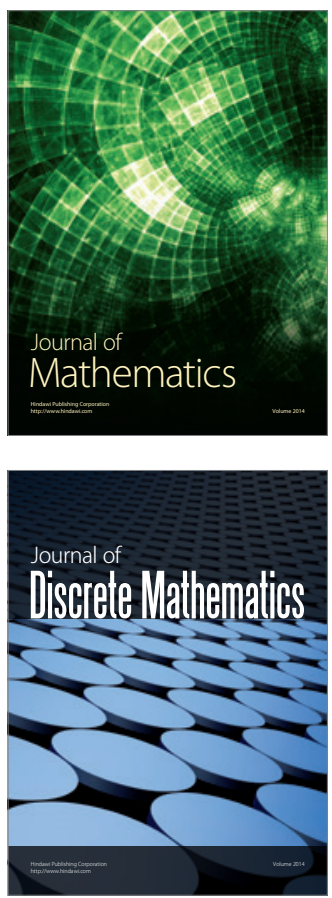

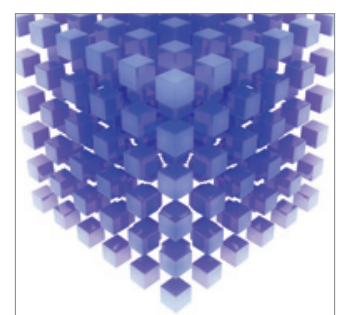

Mathematical Problems in Engineering
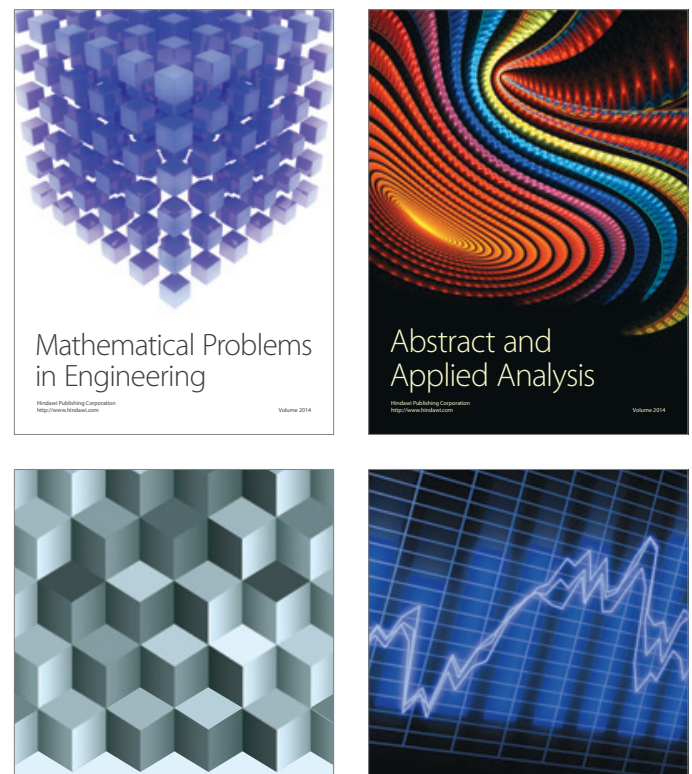

Journal of

Function Spaces

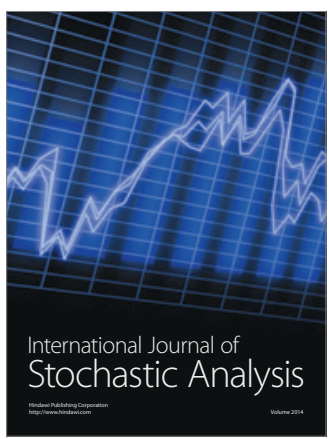

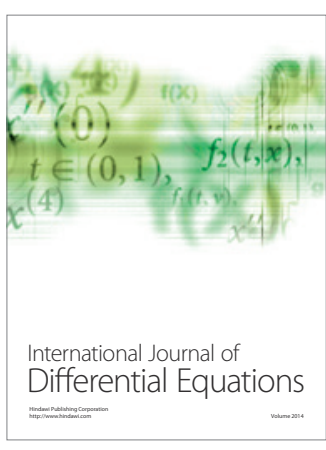
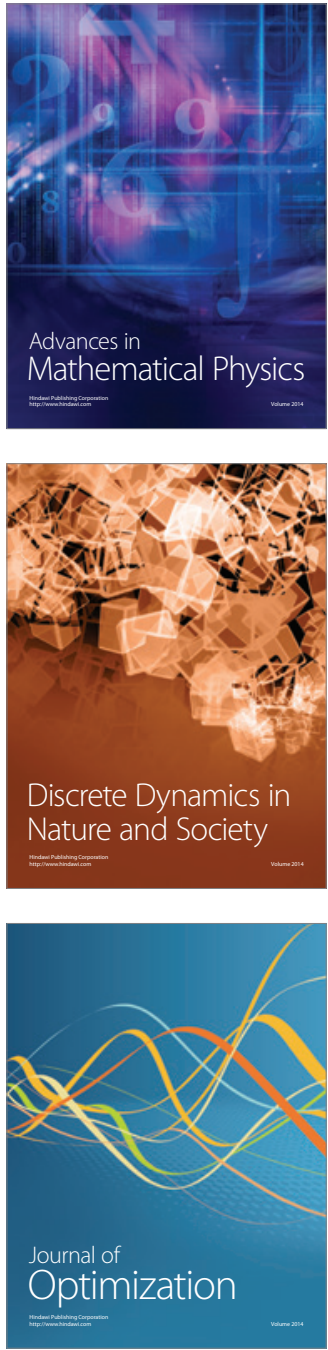